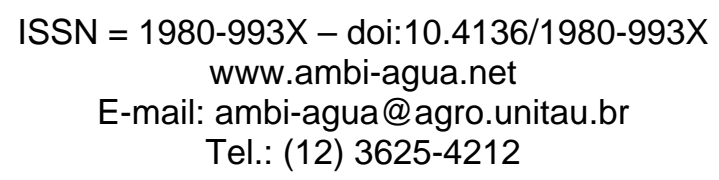

\title{
Sorção de cromo em solos do cerrado goiano, Brasil
}

(doi:10.4136/ambi-agua.143)

\section{Mara Lucia Lemke-de-Castro ${ }^{1}$; Jácomo Divino Borges ${ }^{1}$; Luiz Fernando Coutinho de Oliveira $^{2}$; Cristiane Rodrigues ${ }^{3}$; Cícero Célio de Figueiredo ${ }^{4}$; Welershon José de Castro ${ }^{5}$}

\author{
${ }^{1}$ EA - Escola de Agronomia e Engenharia de Alimentos - UFG \\ E-mail: maralemke@uol.com.br; jacomo.borges@gmail.com \\ ${ }^{2}$ DEG - Departamento de Engenharia - UFLA \\ E-mail:1fco@pq.cnpq.br \\ ${ }^{3}$ Solocria Laboratório Agropecuário Ltda \\ E-mail: crissolocria@yahoo.com.br \\ ${ }^{4}$ FAV - Faculdade de Agronomia e Medicina Veterinária - UNB \\ E-mail: cceliofigueiredo@gmail.com \\ ${ }^{5}$ UEG - Universidade Estadual de Goiás - UnU Morrinhos \\ E-mail: welershon@uol.com.br
}

\section{RESUMO}

O uso agrícola de lodos de curtume, que contêm, normalmente, elevados teores de cromo, e consideráveis teores de matéria orgânica, macronutrientes e micronutrientes, pode contribuir para a melhoria da fertilidade dos solos e nutrição das plantas, além de representar uma forma de descarte do resíduo no ambiente. Objetivou-se, com esta pesquisa, determinar as isotermas de sorção do metal cromo trivalente $\left(\mathrm{Cr}^{+3}\right)$ em Argissolo Vermelho Eutrófico (PVef), Latossolo Vermelho Acriférrico (LVwf), Neossolo Quartzarênico (RQ) e Nitossolo Vermelho Eutroférrico (NVef); verificar, dentre essas classes de solos, qual proporciona maior mobilidade ao cromo, e caracterizar o potencial dos solos agricultáveis do Estado de Goiás quanto ao risco de contaminação de águas subterrâneas por esse metal potencialmente tóxico. Para o estabelecimento de isotermas de sorção foram colocados $5,0 \mathrm{~cm}^{3}$ de amostras de terra fina seca ao ar (TFSA) de cada classe de solo, em triplicata, em béqueres de $250,0 \mathrm{~cm}^{3}$. Foram adicionados, com o auxílio de uma proveta, $50,0 \mathrm{~cm}^{3}$ da solução contendo o metal potencialmente tóxico. As soluções foram preparadas em $\mathrm{CaCl}_{2} \cdot\left(2 \mathrm{H}_{2} \mathrm{O}\right)\left(0,01 \mathrm{~mol} \cdot \mathrm{L}^{-1}\right)$ como eletrólito-suporte e empregando o sulfato básico de cromo como fonte do metal. Foram efetuados ajustes de regressão polinomial entre as concentrações dos teores do metal potencialmente tóxico na solução contaminante em função da concentração do metal na solução filtrada após o equilíbrio. O Neossolo Quartzarênico apresentou uma menor retenção em comparação com as demais classes de solos sendo, portanto, mais vulnerável à contaminação das águas subterrâneas, caso resíduos industriais contendo $\mathrm{Cr}^{+3}$ sejam aplicados como fertilizantes nessa classe de solo.

Palavras-chave: retenção; curtume; Latossolo; Neossolo Quartzarênico.

\section{Sorption of chromium in soils of the Cerrado Goias, Brazil}

\section{ABSTRACT}

Land application of tannery sludge, which usually contain high levels of chromium, and considerable amounts of organic matter, macronutrients and micronutrients may contribute to the improvement of soil fertility and plant nutrition, and constitutes a form of disposal residue in the environment. The objective of this work was to determine the sorption isotherms of metal chromium $\left(\mathrm{Cr}^{+3}\right)$ in a Ultisol, Oxisol Typic Acrustox, Quartzipsamment and Kandic Oxisol, identify soil classes that are prone to chromium mobility, and characterize the potential of agricultural soils of Goiás that are subject to groundwater contamination by the potentially 
toxic metal. For the establishment of sorption isotherms, solutions were prepared at 1:10 in volume. Air dried samples of $5.0 \mathrm{~cm}^{3}$ of each class of soil were placed in triplicates in beakers of $250.0 \mathrm{~cm}^{3}$. A solution containing $50.0 \mathrm{~cm}^{3}$ of the potentially toxic metal was added to solution. The solutions were prepared in $\mathrm{CaCl}_{2} \cdot\left(2 \mathrm{H}_{2} \mathrm{O}\right)\left(0.01 \mathrm{~mol} \cdot \mathrm{L}^{-1}\right)$ as electrolyte support and employing the basic chromium sulphate as a source of metal. Adjustments were made to the polynomial regression between the concentrations of potentially toxic levels of metal contaminants in the solution depending on the concentration of metal in the filtered solution after equilibrium. The Quartzipsamment showed lower retention compared to other classes of soils. Therefore it is more vulnerable to groundwater contamination if industrial wastes containing trivalent chromium are used as fertilizer.

Keywords: retention; tanning; Oxisol Typic Acrustox; Quartzipsamment.

\section{INTRODUÇÃO}

A maioria dos metais tóxicos ocorre naturalmente no solo em baixas concentrações e em formas pouco disponíveis para as plantas e organismos vivos (Resende et al., 1997). Entretanto, com a intensificação dos processos de produção agrícola e a utilização maciça de insumos industrializados e, mais recentemente, com a utilização dos resíduos e subprodutos de processos industriais na agricultura, tem-se observado o enriquecimento de metais tóxicos nos diversos compartimentos ambientais (Alcântara, 1999; Borges, 2003; Conceição e Bonotto, 2005).

A utilização de resíduos industriais no solo, em alguns casos, pode ser recomendada pelo valor corretivo e fertilizante que estes apresentam, bem como pela capacidade da macro e microbiota do solo decompor os materiais orgânicos. É necessário, entretanto, estudar as alterações nas propriedades do solo e a resposta das plantas para avaliar o potencial fertilizante de alguns resíduos e a possível contaminação do ambiente por metais tóxicos (Ferreira et al., 2003).

Os curtumes geram vários resíduos no decorrer do processo produtivo e no tratamento de efluentes. O maior volume de resíduos Classe I (perigosos) constitui-se pela serragem da rebaixadeira de couros "wet blue" e pelo lodo do tratamento primário sem segregação do cromo (Claas e Maia, 1994; Hoinacki, 1989). Cada pele processada gera, em média, $12 \mathrm{~kg}$ de lodo (Claas e Maia, 1994), sendo o lodo do caleiro e o lodo primário da estação de tratamento de efluentes (ETE) gerados em maior quantidade.

Esses resíduos tornam-se altamente poluidores à medida que concentram elevadas cargas orgânica e inorgânica, como fenóis, sulfetos, sódio e cromo. O teor de cromo no lodo de curtume é bastante variável, pois depende do processamento utilizado e da reciclagem ou não dos banhos de curtimento, mas verificam-se valores desde $15,00 \mathrm{mg} . \mathrm{dm}^{3}$ provindos de efluentes com reciclagem (Claas e Maia, 1994), até 5.050,00 $\mathrm{mg} . \mathrm{dm}^{3}$ para efluentes de curtume de "wet blue" sem reciclagem de banhos (Borges, 2003). De acordo com a Resolução do Conselho Nacional do Meio Ambiente (CONAMA) no 420/09 o valor de orientação de investigação industrial para cromo é de $400 \mathrm{mg} \cdot \mathrm{kg}^{-1}$ de peso seco de solo e de $50 \mu \mathrm{g} . \mathrm{L}^{-1}$ de cromo nas águas subterrâneas (Brasil, 2009).

O uso agrícola de lodos de curtume pode contribuir para a melhoria da fertilidade dos solos e nutrição das plantas (Konrad e Castilhos, 2002; Ferreira et al., 2003), além de representar uma forma de descarte do resíduo no ambiente (Borges, 2003). Quanto a esse último aspecto, deve-se destacar a necessidade de critérios técnicos para a aplicação desse tipo de resíduo na agricultura, uma vez que essa prática, quando utilizada de forma inadequada, pode conduzir a elevados valores de pH (Selbach et al., 1991), sais solúveis (Aquino Neto e Camargo, 2000; Konrad e Castilhos, 2002) e cromo nos solos tratados (Aquino Neto e Camargo, 2000), o que pode comprometer a sustentabilidade agrícola e o uso futuro dessas áreas (Borges, 2003). Philippi Júnior e Aguiar (2005) destacam a necessidade de controles rigorosos na 
implantação de áreas para disposição final de resíduos sólidos industriais, observando tipo de solo, relevo, clima, entre outras variáveis.

Objetivou-se, na presente pesquisa, determinar as isotermas de sorção do metal cromo $\left(\mathrm{Cr}^{+3}\right)$ em Argissolo Vermelho Eutrófico (PVef), Latossolo Vermelho Acriférrico (LVwf), Neossolo Quartzarênico (RQ) e Nitossolo Vermelho Eutroférrico (NVef); verificar, dentre essas classes de solos, qual oferece maior mobilidade ao cromo, e caracterizar o potencial dos solos agricultáveis do Estado de Goiás quanto ao risco de contaminação de águas subterrâneas por esse metal potencialmente tóxico.

\section{MATERIAL E MÉTODOS}

\subsection{Amostragem dos solos}

Foram coletadas amostras de solos com características contrastantes em quatro perfis, classificados conforme o Sistema Brasileiro de Classificação de Solos (SiBCS) (Embrapa, 2006). A localização geográfica dos pontos de coleta, dentro do Estado de Goiás, está detalhada na Figura 1. Observa-se que as coletas foram realizadas da porção central à porção sudoeste do território goiano, em uma área tipicamente de domínio cerrado. Foram selecionados para o estudo os seguintes solos: Argissolo Vermelho Eutrófico (PVef) (P.1), Latossolo Vermelho Acriférrico (LVwf) (P.2), Neossolo Quartzarênico (RQ) (P.3) e Nitossolo Vermelho Eutroférrico (NVef) (P.4). Os perfis foram selecionados em função da predominância das áreas agricultáveis do Estado de Goiás.

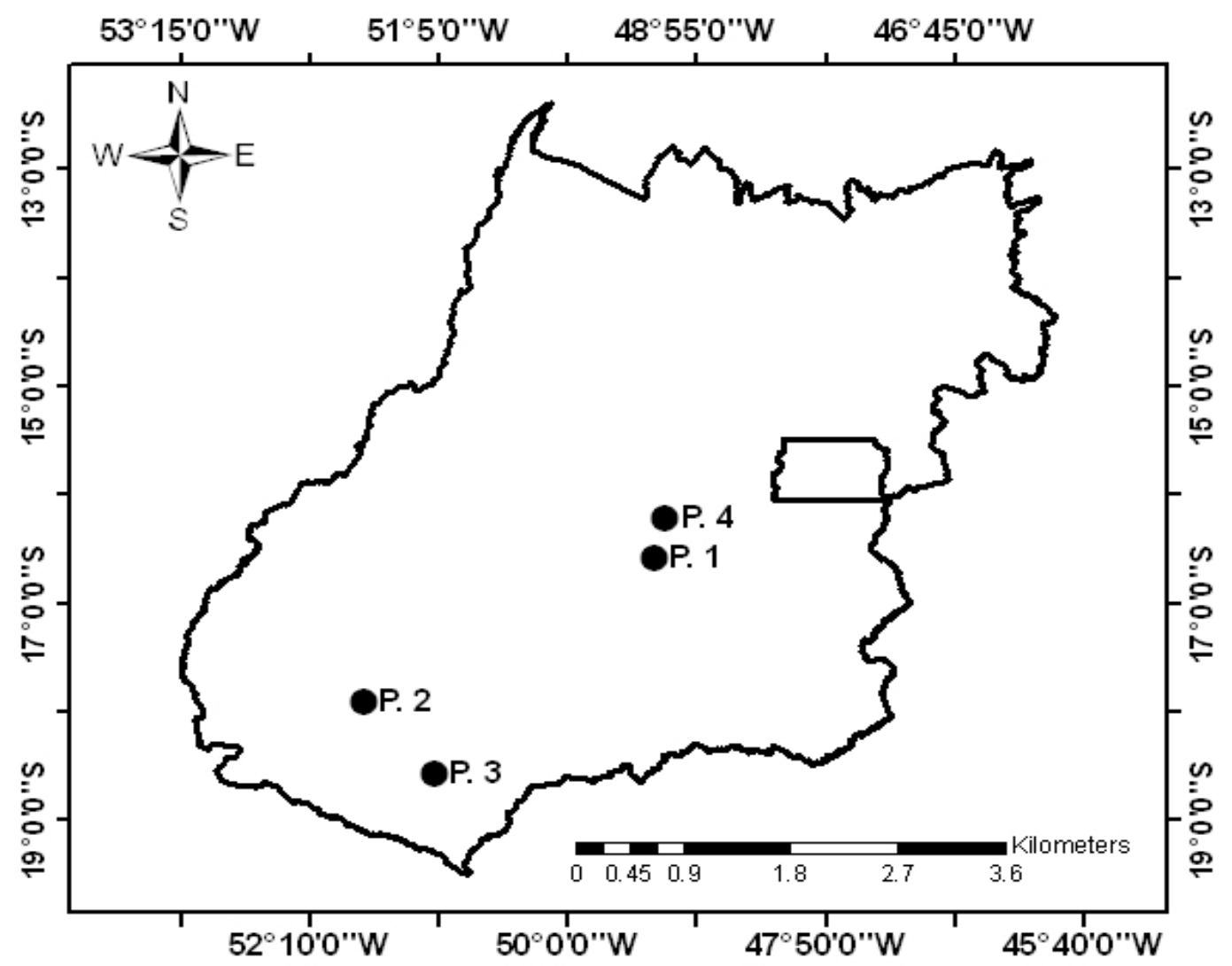

Figura 1. Localização das diferentes classes de solo, no Estado de Goiás. P.1 Argissolo Vermelho Eutrófico (PVef) (Goiânia), P.2 - Latossolo Vermelho Acriférrico (LVwf) (Jataí), P.3 - Neossolo Quartzarênico (RQ) (Caçú) e P.4 - Nitossolo Vermelho Eutroférrico (NVef) (Ouro Verde). 
Para cada classe de solo foram realizadas as caracterizações dos perfis abertos para essa finalidade. As caracterizações físicas e químicas dos solos estudados foram realizadas segundo as metodologias preconizadas por Santos et al. (2005) e Embrapa (1997 e 1999). Foram coletadas amostras deformadas e indeformadas, com três repetições, no horizonte diagnóstico subsuperficial, para evitar ou reduzir os efeitos de sorção produzidos pela matéria orgânica presente, geralmente em maior quantidade na superfície do solo.

Os pontos de coletas foram previamente selecionados em áreas com desenvolvimento de atividades agrícolas e com base na ocorrência das classes de solo já estudadas por outros pesquisadores, e com características comprovadamente contrastantes (Calil, 2003; Embrapa, 2004; Oliveira, 2007; Rodrigues, 2008). Para as análises químicas, granulométrica e de massa específica de partículas foram obtidas as amostras deformadas, as quais foram retiradas com auxílio de um trado do tipo "holandês". Utilizando-se um amostrador de Uhland foram retiradas as amostras indeformadas de solo, com a finalidade de se determinar a massa específica do solo.

\subsection{Caracterizações físicas, químicas e mineralógicas}

Foram realizadas as análises mineralógicas da fração argila, como complemento, para se avaliar o tipo de argilomineral que estava presente nas classes de solos estudadas, segundo Rodrigues (2008). As amostras de solo foram submetidas à moagem prévia em moinho orbital até a sua total fragmentação (100\% passante na peneira 325 mesh), com o objetivo de obter material representativo de granulação bem fina. Concluída essa etapa, parte do material foi analisada no difratômetro de raios-X (Difração de Raios-X), no Laboratório de Mecânica das Rochas da Divisão de Geotecnia de FURNAS - Centrais Elétricas, S/A, localizado no município de Aparecida de Goiânia, Goiás.

As caracterizações físicas e químicas desses solos foram realizadas no Laboratório de Análise de Solo e Foliar da Escola de Agronomia e Engenharia de Alimentos da Universidade Federal de Goiás, e as concentrações de metais das soluções foram determinadas no Solocria Laboratório Agropecuário Ltda., de acordo com as metodologias preconizadas pela Embrapa (1997 e 1999). A caracterização química do solo foi obtida pela determinação dos teores de cátions do complexo sortivo, $\mathrm{pH}$ em água e em $\mathrm{KCl}$, fósforo disponível e óxidos $\left(\mathrm{SiO}_{2}, \mathrm{Al}_{2} \mathrm{O}_{3}\right.$, $\mathrm{Fe}_{2} \mathrm{O}_{3}, \mathrm{TiO}_{2}$ e $\mathrm{P}_{2} \mathrm{O}_{5}$ ) extraídos através da metodologia do ataque sulfúrico, segundo Embrapa (1997). Ele decompõe somente os minerais secundários (argilominerais e óxidos de ferro e alumínio) que permitiram a obtenção dos índices de intemperismo $\mathrm{K}_{\mathrm{i}}$ e $\mathrm{K}_{\mathrm{r}}$. Esses índices correlacionam com a composição química presente no solo, contribuindo para caracterizar o grau de intemperização. Esses índices estão diretamente relacionados com o grau de alteração do solo, quanto maiores seus valores, menores serão os graus de intemperismo.

\subsection{Isotermas de sorção}

Para o estabelecimento de isotermas de sorção, as amostras deformadas dos solos, inicialmente, foram destorroadas e secas à sombra por um período suficiente para ocorrer a perda de umidade necessária para, posteriormente, serem passadas em uma peneira com malha de 2,0 mm, obtendo, assim, as amostras de terra fina seca ao ar (TFSA). Foram preparadas soluções de solo diluídas em soluções de concentração variada contendo o metal, na proporção de 1:10, em volume, de acordo com Alcântara (1999), Dias et al. (2003), Falone e Vieira (2004) e Ferri et al. (2005). Foram colocados 5,0 $\mathrm{cm}^{3}$ de amostras de cada classe de solo, em triplicata, em béqueres de $250 \mathrm{~cm}^{3}$. Adicionou-se, com o auxílio de uma proveta, $50,0 \mathrm{~cm}^{3}$ da solução contendo o metal potencialmente tóxico nas seguintes concentrações: solução A [0,02 mg.. $\left.\mathrm{L}^{-1}\right]$; solução B [60,00 mg. $\left.\mathrm{L}^{-1}\right]$; solução C $\left[285,00 \mathrm{mg} \cdot \mathrm{L}^{-1}\right]$; solução D $\left[600,00 \mathrm{mg} \cdot \mathrm{L}^{-1}\right]$ e solução $\mathrm{E}\left[1.700,00 \mathrm{mg} \cdot \mathrm{L}^{-1}\right]$. As soluções foram preparadas em $\mathrm{CaCl}_{2}\left(2 \mathrm{H}_{2} \mathrm{O}\right)\left(0,01\right.$ mol.L $\left.\mathrm{L}^{-1}\right)$ como eletrólito-suporte, conforme descrito por Falone e Vieira 
(2004), Lima (2004) e Ferri et al. (2005), e empregando-se o sulfato básico de cromo como fonte do metal, respeitando-se as concentrações máximas aceitáveis em diferentes países (Arantes et al., 2006; Chaves et al., 2008; Lemke-de-Castro, 2009).

Com a finalidade de aumentar o contato da solução com o solo, os béqueres contendo as amostras foram agitados manualmente, conforme metodologia adaptada de Mellis e Rodella (2008). Após a agitação, as amostras foram acondicionadas em uma caixa de isopor, e mantidas nesta por um período de 48 horas a uma temperatura de $25^{\circ} \mathrm{C} \pm 2{ }^{\circ} \mathrm{C}$, para se obter a concentração de equilíbrio, conforme descrito por Jordão et al. (2000), Arantes et al. (2006) e Alves (2008). A temperatura no interior da caixa foi monitorada com o auxílio de um termômetro com cabo (termômetro de vacina), com visualização na parte externa da caixa.

Após o equilíbrio, fez-se a filtragem do sobrenadante, e as alíquotas foram transferidas para frascos de vidro âmbar e armazenadas sob refrigeração até o momento da determinação da concentração do metal em solução, pela técnica da espectrometria de absorção atômica. As concentrações de metais das soluções foram determinadas de acordo com as metodologias preconizadas pela Embrapa (1997 e 1999). A concentração do metal adsorvido ao solo foi obtida pelo emprego da Equação 1, de acordo com Lemke-de-Castro (2009) e Oliveira et al. (2010a; 2010b).

$$
\mathrm{C}_{\mathrm{s}}=\left(\mathrm{C}_{\mathrm{i}}-\mathrm{C}_{\mathrm{f}}\right) \frac{\mathrm{Vol}}{\mathrm{m}}
$$

em que:

$\mathrm{C}_{\mathrm{s}}=$ concentração do metal adsorvido ao solo (mg. $\left.\mathrm{kg}^{-1}\right)$;

$\mathrm{C}_{\mathrm{i}}$ e $\mathrm{C}_{\mathrm{f}}=$ concentração inicial e final da solução $\left(\mathrm{mg} . \mathrm{L}^{-1}\right)$;

$\mathrm{m}=$ massa da TFSA adicionada ao Becker $(\mathrm{kg})$;

Vol = volume da solução adicionada ao Becker (L).

Obtiveram-se as concentrações adsorvidas para cada valor de $\mathrm{C}_{\mathrm{i}}$. para as diferentes classes de solo. De posse dessas informações, ajustaram-se as isotermas de sorção de Freundlich no modelo potencial (Equação 2) e linear de acordo com Lemke-de-Castro (2009) e Oliveira et al. (2010a; 2010b).

$$
\mathrm{C}_{\mathrm{s}}=\mathrm{K}_{\mathrm{f}} \mathrm{C}_{\mathrm{w}}^{\mathrm{N}}
$$

em que:

$\mathrm{C}_{\mathrm{w}}=$ concentração do soluto em solução $\left(\mathrm{mg} \cdot \mathrm{L}^{-1}\right)$;

$\mathrm{K}_{\mathrm{f}}$ e $\mathrm{N}=$ coeficiente e expoente da isoterma de Freundlich.

Quando o expoente $\mathrm{N}$ for unitário, tem-se uma isoterma linear que corresponde a um caso especial da isoterma de Freundlich (Freeze e Cherry, 1979). Nesse caso, segundo Correia et al. (2007) e Arantes et al. (2006), o coeficiente de proporcionalidade da isoterma de Freundlich é chamado de coeficiente de partição $\left(K_{d}\right)$. Os valores de $K_{d}$ têm importância fundamental do ponto de vista ambiental, pois refletem a afinidade de alguns elementos, como os metais pesados, pelos constituintes da fase sólida do solo (Alleoni et al., 2009).

De acordo com Lemke-de-Castro (2009) e Oliveira et al. (2010a; 2010b), de posse do coeficiente angular da isoterma de sorção linear $\left(\mathrm{K}_{\mathrm{d}}\right)$ determinou-se o respectivo fator de retardamento pelo emprego da Equação 3.

$$
\mathrm{R}=1+\underline{\mathrm{D}_{\underline{\mathrm{s}}}} \mathrm{K}_{\mathrm{d}}
$$


em que:

$\mathrm{K}_{\mathrm{d}}=$ coeficiente de partição $\left(\mathrm{m}^{3} \mathrm{~kg}^{-1}\right)$;

$\mathrm{P}=$ porosidade total do solo $\left(\mathrm{m}^{3} \mathrm{~m}^{-3}\right)$

$\mathrm{D}_{\mathrm{s}}=$ massa específica do solo $\left(\mathrm{kg} \mathrm{m}^{-3}\right)$.

\subsection{Análise estatística}

Foram efetuados ajustes de regressão polinomial entre as concentrações dos teores de cromo na solução contaminante (variável independente) pela sua concentração na solução filtrada após o equilíbrio (variável dependente). O modelo adotado foi o que apresentou o maior coeficiente de determinação $\left(\mathrm{R}^{2}\right)$. De acordo com Alleoni et al. (2009), o ajuste dos resultados de adsorção à isoterma de Freundlich pode ser avaliado pelo $\mathrm{R}^{2}$.

\section{RESULTADOS E DISCUSSÃO}

\subsection{Análises físicas, químicas e mineralógicas}

O solo das classes Argissolo Vermelho Eutrófico (76,1\%), Latossolo Vermelho Acriférrico $(70,4 \%)$ e Nitossolo Vermelho Eutroférrico $(78,9 \%)$ apresentou uma alta porcentagem da fração argila, acima de $70 \%$, diferente do valor analisado na classe Neossolo Quartzarênico que apresentou uma grande porcentagem da fração areia $(79,0 \%)$.

Os resultados das análises químicas sugerem que o Argissolo Vermelho Eutrófico $\left(11,43 \mathrm{cmol}_{\text {c. }} \mathrm{dm}^{-3}\right)$ e o Nitossolo Vermelho Eutroférrico $\left(9,27 \mathrm{cmol}_{\mathrm{c} .} \mathrm{dm}^{-3}\right)$ são cauliníticos com boa retenção de cátions $(8,61<\mathrm{T}<15)$, enquanto que o Latossolo Vermelho Acriférrico $\left(3,65 \mathrm{cmol}_{\mathrm{c} .} \mathrm{dm}^{-3}\right)$ e o Neossolo Quartzarênico $\left(3,43 \mathrm{cmol}_{\mathrm{c} .} \mathrm{dm}^{-3}\right)$ são solos gibbsíticos/oxídicos que possuem baixa capacidade de retenção de cátions $(1,61<\mathrm{T}<4,3)$ e que os valores do $\mathrm{pH}$, tanto em água quanto em $\mathrm{KCl}$, indicam uma acidez fraca a neutra nos solos das classes Argissolo Vermelho Eutrófico $\left(\mathrm{pH}_{\mathrm{H}_{2} \mathrm{O}} 6,60\right.$ e $\left.\mathrm{pH}_{\mathrm{KCl}} 5,00\right)$, Neossolo Quartzarênico $\left(\mathrm{pH}_{\mathrm{H}_{2} \mathrm{O}} 6,54\right.$ e $\left.\mathrm{pH}_{\mathrm{KCl}} 4,67\right)$ e Nitossolo Vermelho Eutroférrico $\left(\mathrm{pH}_{\mathrm{H}_{2} \mathrm{O}} 6,00\right.$ e $\mathrm{pH}_{\mathrm{KCl}}$ $5,70)$, e uma acidez elevada, com predominância de cargas positivas $(\Delta \mathrm{pH}$ positivo 1,20$)$, no solo da classe Latossolo Vermelho Acriférrico $\left(\mathrm{pH}_{\mathrm{H}_{2} \mathrm{O}} 3,80\right.$ e $\left.\mathrm{pH}_{\mathrm{KCl}} 5,00\right)$. Esse conjunto de fatores $(\mathrm{T}, \mathrm{pH}$ e $\Delta \mathrm{pH})$ sugerem que o Latossolo Vermelho Acriférrico deveria apresentar as menores retenções, porém os resultados encontrados foram exatamente o inverso, sugerindo que a mineralogia desse solo possui fatores que permitem uma adsorção específica, conforme descrito por Cunha et al. (1994) e Muniz et al. (1996).

A mineralogia das argilas do Argissolo Vermelho Eutrófico $\left(K_{i} 1,5\right.$ e $\left.K_{r} 1,02\right)$ e do Nitossolo Vermelho Eutroférrico $\left(\mathrm{K}_{\mathrm{i}} 1,73\right.$ e $\mathrm{K}_{\mathrm{r}}$ 1,17) demonstram que tem como principal mineral secundário a caulinita, seguido de gibbsita, e hematita no caso do Nitossolo Vermelho Eutroférrico e de ilita e magnetita no Argissolo Vermelho Eutrófico, estando esta mineralogia de acordo com o previsto pela análise do $\mathrm{K}_{\mathrm{i}}$ e do $\mathrm{K}_{\mathrm{r}}$.

Observou-se a predominância mineralógica oxídica, para o Latossolo Vermelho Acriférrico $\left(\mathrm{K}_{\mathrm{i}} 0,68\right.$ e $\mathrm{K}_{\mathrm{r}}$ 0,40), concordando com os resultados das análises do $\mathrm{K}_{\mathrm{i}}$ e do $\mathrm{K}_{\mathrm{r}}$. Não foi realizado o difratograma do Neossolo Quartzarênico $\left(K_{i} 0,74\right.$ e $\left.K_{r} 0,45\right)$, devido à baixa porcentagem da fração argila encontrada nesse solo e, por apresentar valores de $\mathrm{K}_{\mathrm{i}}$ e $\mathrm{K}_{\mathrm{r}}$ $\leq 0,75$, afere-se que haja uma predominância oxídica.

\subsection{Ensaios de sorção do metal potencialmente tóxico nos solos}

A análise de variância (ANOVA) dos valores médios do teor de sorção indicou uma variação muito grande entre as classes de solos, entre as variações de concentração das soluções e na interação solo versus solução ( $\operatorname{Pr}>\mathrm{F}$ ), o que já era esperado, pois foram utilizadas soluções de concentrações crescentes em cada tratamento e classes de solos com características contrastantes. No geral, essas variações foram superiores a 99\%. 
A diferença entre as repetições dos tratamentos demonstraram pouca variação, sendo consideradas estatisticamente iguais, ao nível de $5 \%$ de significância, utilizando o teste de Tukey. O Latossolo Vermelho Acriférrico apresentou maior capacidade de retenção para o metal potencialmente tóxico avaliado, sendo que a solução $\mathrm{E}$ (de maior concentração) apresentou o maior poder sortivo. O metal potencialmente tóxico avaliado apresentou correlação positiva com a fração argila $(0,80)$ e com o teor de carbono orgânico $(0,59)$.

Constatou-se que o teor de sorção do cromo trivalente, entre os solos avaliados, ao nível de significância de 5\%, pelo teste de Tukey, em ordem decrescente, foi: Latossolo Vermelho Acriférrico $>$ Nitossolo Vermelho Eutroférrico $=$ Argissolo Vermelho Eutrófico $>$ Neossolo Quartzarênico.

Vários autores demonstram que há correlação positiva entre sorção de íons no solo e óxidos, oxihidróxidos e hidróxidos componentes da fração argila, principalmente óxidos de ferro e alumínio (Cunha et al., 1994; Muniz et al., 1996; Ladeira et al., 2002; Eberhardt et al., 2008). Em solos altamente intemperizados, esses óxidos possuem forma bem cristalizada e podem apresentar maior superfície específica (2,9 vezes) e, por isso, gerar maior poder de sorção (Eberhardt et al., 2008). O maior poder de sorção do Latossolo Vermelho Acriférrico pode ser justificado pelo maior teor de óxido de ferro $(25,5 \%)$ e alumínio $(22,5 \%)$ e elevada fração argila (70,4\%), associados ao maior teor de carbono orgânico $\left(7,00 \mathrm{~g}^{\mathrm{kg}} \mathrm{kg}^{-1}\right)$. Essa constatação confirma as observações de Freeze e Cherry (1979), que verificaram que as quantidades de matéria orgânica e argilominerais aumentam a capacidade de adsorção dos solos. Cunha et al. (1994) observaram correlação positiva entre óxidos de ferro e de alumínio com a sorção de zinco, enquanto que Eberhardt et al. (2008), em pesquisas com Latossolos de cerrados, verificaram que os óxidos de ferro e de alumínio livres e amorfos e a mineralogia gibbsítica mostraram-se relacionadas com a sorção de fósforo nos solos.

O Neossolo Quartzarênico (RQ) possui uma menor capacidade de retenção para o metal potencialmente tóxico avaliado e, quando associado à movimentação de água nessa classe de solo, há um maior risco de contaminação das águas subterrâneas. A baixa retenção de metais nesse solo está associada à baixa porcentagem da fração argila $(15,0 \%)$, responsável pelos sítios de troca (baixa CTC $3,43 \mathrm{cmol}_{\mathrm{c} .} \mathrm{dm}^{-3}$ ) e pelo tipo de argilomineral encontrado (predomínio de óxidos), concordando com Sodré et al. (2001); Dias et al. (2003) e Souza et al. (2006). No entanto, nos solos com maiores concentrações de argila (Argissolo Vermelho Eutrófico PVef, Latossolo Vermelho Acriférrico - LVwf e Nitossolo Vermelho Eutroférrico - NVef), observa-se uma maior propensão no que se refere à sorção do metal potencialmente tóxico no solo.

O comportamento das isotermas ajustadas para o cromo trivalente $\left(\mathrm{Cr}^{+3}\right)$ pode ser visualizado na Figura 2, que representa as respectivas isotermas, para as diferentes classes de solo analisadas. Verifica-se que as isotermas potenciais apresentam um melhor ajuste quando comparadas com a linear, com coeficientes de determinação $\left(\mathrm{R}^{2}\right)$ acima de 0,99 . Entretanto, a forma linearizada do modelo de Freundlich tem sido usada em diversos estudos, principalmente com metais pesados (Alleoni et al., 2009). 


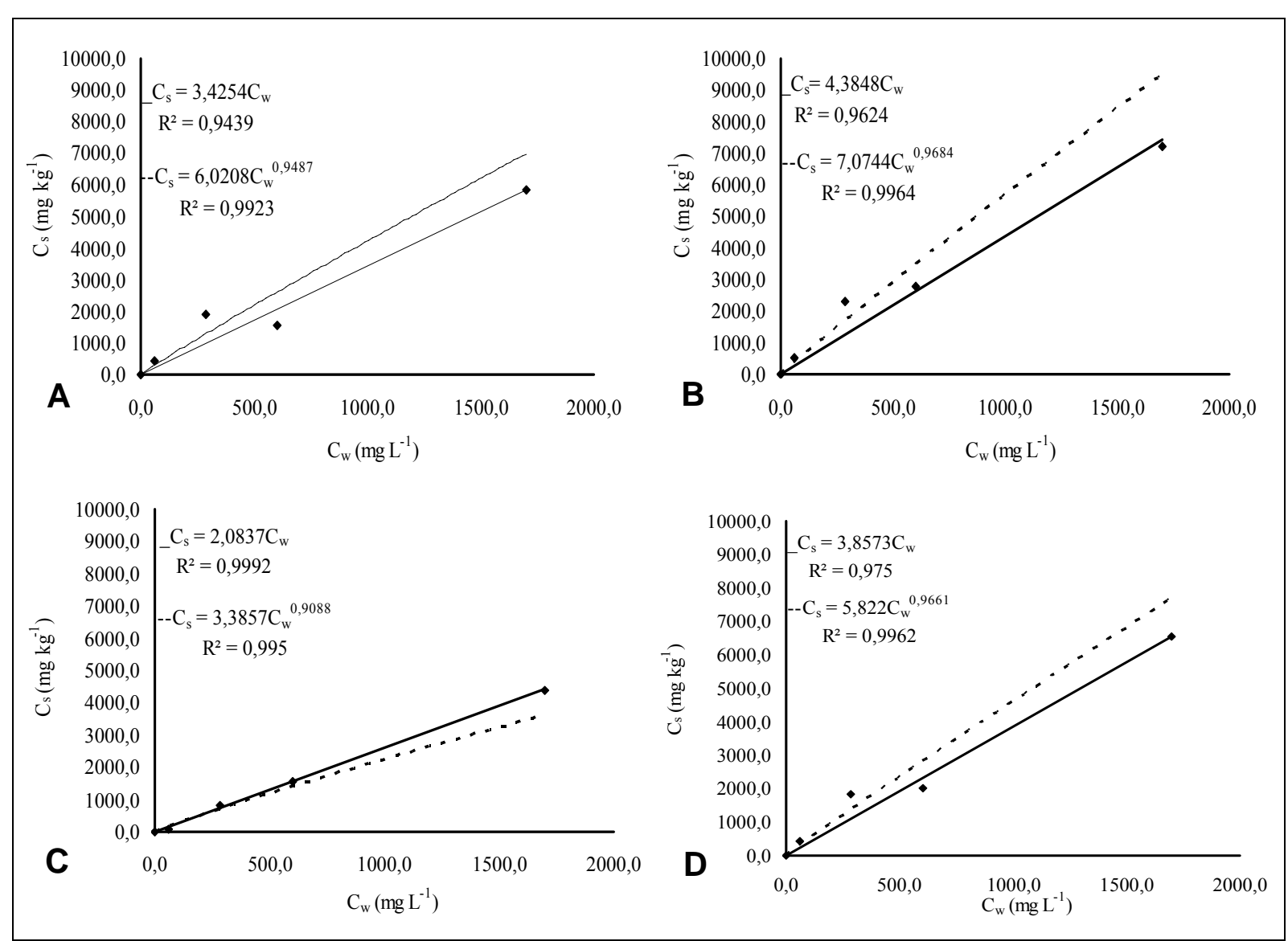

Figura 2. Isotermas de sorção potencial e linear do cromo trivalente $\left(\mathrm{Cr}^{+3}\right)$, a $25^{\circ} \mathrm{C} \pm 2{ }^{\circ} \mathrm{C}$, em diferentes classes de solos agricultáveis, no Cerrado do Estado de Goiás. A - Argissolo Vermelho Eutrófico (PVef); B -Latossolo Vermelho Acriférrico (LVwf); C - Neossolo Quartzarênico (RQ) e D Nitossolo Vermelho Eutroférrico (NVef).

\section{CONCLUSÕES}

As isotermas de sorção ajustadas descrevem o comportamento de sorção do cromo trivalente para as diferentes classes de solo agricultáveis encontradas no cerrado do Estado de Goiás;

O Neossolo Quartzarênico apresentou uma menor retenção em comparação às demais classes de solos sendo, portanto, mais vulnerável à contaminação das águas subterrâneas caso resíduos industriais contendo cromo trivalente sejam aplicados como fertilizantes nessa classe de solo.

\section{AGRADECIMENTOS}

Ao Conselho Nacional de Desenvolvimento Científico e Tecnológico (CNPq), pelo aporte financeiro ao projeto de pesquisa "Retenção e transporte de metais pesados em solos agricultáveis do estado de Goiás", coordenado pelo professor Dr. Luiz Fernando Coutinho de Oliveira.

\section{REFERÊNCIAS}

ALCÂNTARA, M. A. K. Eluviação de crômio (III) de resíduos de curtume em colunas de dois Latossolos com diferentes texturas. 1999. 201f. Tese (Doutorado em Engenharia Agrícola: Água e Solo) - Faculdade de Engenharia Agrícola, Universidade Estadual de Campinas, Campinas, 1999. 
ALLEONI, L. R. F.; MELLO, J. W. V.; ROCHA, W. S. D. Eletroquímica, adsorção e troca iônica no solo. In: MELO, V. F.; ALLEONI, L. R. F. Química e mineralogia do solo: aplicações. Viçosa, MG: SBCS, 2009. p. 69-130.

ALVES, D. N. B. Remoção de ferro em água de irrigação através de filtragem em areia e zeolita. 2008. 97f. Tese (Doutorado em Engenharia Agrícola: Engenharia de Água e Solo) - Universidade Federal de Lavras, Lavras, 2008.

AQUINO NETO, V.; CAMARGO, O. A. Crescimento e acúmulo de cromo em alface cultivada em dois latossolos tratados com $\mathrm{CrCl}_{3}$ e resíduos de curtume. Revista Brasileira de Ciência do Solo, Viçosa, v. 24, p. 225-235, 2000.

ARANTES, S. A. C. M.; LIMA, J. M.; NÓBREGA, J. C. A.; GUILHERME, L. R. G.; JULIÃO, L. G. F.; JESUS, E. A. Sorção de atrazina em solos representativos da subbacia do rio das Mortes, MG. Pesticidas: Revista de Ecotoxicologia e Meio Ambiente, Curitiba, v. 16, p. 101-110, 2006.

BORGES, J. D. Efeitos do lodo de curtume nas culturas do milho (Zea mays L.) e do capim braquiarão [Brachiaria brizantha (Hochst Ex A. Rick) Stapf.] cultivar marandu em Latossolo Vermelho-amarelo. 2003. 244f. Tese (Doutorado em Agronomia: Produção Vegetal) - Escola de Agronomia e Engenharia de Alimentos, Universidade Federal de Goiás, Goiânia, 2003.

BRASIL. Ministério do Meio Ambiente. Conselho Nacional do Meio Ambiente. Resolução $\mathbf{N}^{\circ}$ 420, de 28 de dezembro de 2009. Dispõe sobre critérios e valores orientadores de qualidade do solo quanto à presença de substâncias químicas e estabelece diretrizes para o gerenciamento ambiental de áreas contaminadas por essas substâncias em decorrência de atividades antrópicas. Brasília: MMA, 2009. 16p.

CALIL, P. M. (Coord.). Levantamento de reconhecimento de alta intensidade dos solos, avaliação da aptidão agrícola e uso atual das terras da bacia de drenagem do Córrego das Pedras e do Ribeirão Jurubatuba no Estado de Goiás. Goiânia: AGENCIARURAL, 2003. 138p.

CHAVES, L. H. G.; SOUZA, R. S.; TITO, G. A. Adsorção de zinco em argissolos do estado da Paraíba: efeito do pH. Revista Ciência Agronômica, Fortaleza, v. 39, n. 4, p. 511516, 2008.

CLAAS, I. C.; MAIA, R. A. Manual básico de resíduos industriais de curtume. Porto Alegre: SENAI/RS, 1994. 664 p.

CONCEIÇÃO, F. T. DA; BONOTTO, D. M. Transferência de metais pesados, flúor e radionuclídeos para solos agrícolas na bacia do rio Corumbataí (SP). Geociências, São Paulo, v. 24, n. 1, p. 67-76, 2005.

CORREIA, F. V.; MERCANTE, F. M.; FABRÍCIO, A. C. Adsorção de atrazina em solo tropical sob plantio direto e convencional. Pesticidas: Revista de Ecotoxicologia e Meio Ambiente, Curitiba, v. 17, n. 1, p. 37-46, 2007.

CUNHA, R. C. A.; CAMARGO, O. A.; KINJO, T. Retenção de zinco em solos paulistas. Bragantia, Campinas, v. 53, n. 2, p. 291-301, 1994.

DIAS, N. M. P.; ALLEONI, L. R. F.; CASAGRANDE, J. C.; CAMARGO, O. A. Energia livre da reação de adsorção de cádmio em latossolos ácricos. Ciência Rural, Santa Maria, v. 33, n. 5, p. 829-834, 2003. 
EBERHARDT, D. N.; VENDRAME, P. R. S.; BECQUER, T.; GUIMARÃES, M. F. Influência da granulometria e da mineralogia sobre a retenção do fósforo em Latossolos sob pastagens do cerrado. Revista Brasileira de Ciência do Solo, Viçosa, v. 32, n. 3, p. 1009-1016, 2008.

EMPRESA BRASILEIRA DE PESQUISA AGROPECUÁRIA - EMBRAPA. Centro Nacional de Pesquisa de Solos. Manual de métodos de análise de solos. 2. ed. Rio de Janeiro: EMBRAPA, 1997. 212 p.

EMPRESA BRASILEIRA DE PESQUISA AGROPECUÁRIA - EMBRAPA. Manual de análises químicas de solos, plantas e fertilizantes. Brasília: Embrapa Solos/Embrapa Informática Agropecuária/Embrapa Comunicação para Transferência de Tecnologia, 1999. 370p.

EMPRESA BRASILEIRA DE PESQUISA AGROPECUÁRIA - EMBRAPA. Reunião de correlação, classificação e aplicação de levantamentos de solos da região CentroOeste - RCC-GO/MT. Rio de Janeiro: Embrapa Solos, 2004. 104p. (Boletim de Pesquisa e Desenvolvimento, 55).

EMPRESA BRASILEIRA DE PESQUISA AGROPECUÁRIA - EMBRAPA. Centro Nacional de Pesquisa de Solos. Sistema Brasileiro de Classificação de Solos. 2. ed. Rio de Janeiro: Embrapa Solos, 2006.

FALONE, S. Z.; VIEIRA, E. M. Adsorção/dessorção do explosivo tetril em turfa e em Argissolo Vermelho amarelo. Química Nova, São Carlos, v. 27, n. 6, p. 849-854, 2004.

FERREIRA, A. S.; CAMARGO, F. A. O.; TEDESCO, M. J.; BISSANI, C. A. Alterações de atributos químicos e biológicos de solo em rendimento de milho e soja pela utilização de resíduos de curtume e carbonífero. Revista Brasileira de Ciência do Solo, Viçosa, v. 27, n. 4, p. 755-763, 2003.

FERRI, M. V. W.; GOMES, J.; DICK, D. P.; SOUZA, R. F. de; VIDAL, R. A. Sorção do herbicida acetochlor em amostras de solo, ácidos húmicos e huminas de argissolo submetido à semeadura direta e ao preparo convencional. Revista Brasileira de Ciência do Solo, Viçosa, v. 29, n. 5, p. 705-714, 2005.

FREEZE, A.; CHERRY, J. A. Groundwater. New Jersey: Prentice-Hall, 1979, 604p.

HOINACKI, E. Peles e couros. 2. ed. Porto Alegre: SENAI/RS, 1989. 319p.

JORDÃO, C. P.; ALVES, N. M.; PEREIRA, J. L.; BELLATO, C. R. Adsorção de íons Cu ${ }^{2+}$ em latossolo vermelho-amarelo húmico. Química Nova, São Carlos, v. 23, n. 1, p. 5-11, 2000 .

KONRAD, E. E.; CASTILHOS, D. D. Alterações químicas do solo e crescimento do milho decorrente da adição do lodo de curtume. Revista Brasileira de Ciência do Solo, Campinas, v. 26, p. 257-265, 2002.

LADEIRA, A. C. Q.; CIMINELLI, V. S. T.; NEPOMUCENO, A. L. Seleção de solos para a imobilização de arsênio. Revista Escola de Minas, Ouro Preto, v. 55, n. 3, p. 215-221, 2002.

LEMKE-DE-CASTRO, M. L. Retenção de metais pesados em solos agricultáveis do Estado de Goiás. 2009. 83f. Dissertação (Mestrado em Agronomia: Solo e Água) Universidade Federal de Goiás, Goiânia, 2009. 
LIMA, D. M. Sorção e deslocamento miscível da antrazina em amostras de latossolos. 2004. 66f. Dissertação (Mestrado em Agronomia: Solos e Nutrição de Plantas) -Universidade Federal de Lavras, Lavras, 2004.

MELLIS, E. V.; RODELLA, A. A. Influência do tempo de agitação na adsorção de $\mathrm{Cd}, \mathrm{Cu}$, Ni e Zn em Latossolo tratado com lodo de esgoto. Bragantia, Campinas, v. 67, n. 4, p. 977-982, 2008.

MUNIZ, L. L. F.; JORDÃO, C. P.; BRUNE, W.; PEREIRA, J. L.; REIS, E. L. Retenção de zinco em solos do Vale do Aço mineiro, afetada pela remoção de matéria orgânica, óxido de ferro e óxido de manganês. Química Nova, São Paulo, v. 19, n. 5, p. 464-468, 1996.

OLIVEIRA, L. F. C.; LEMKE-DE-CASTRO, M. L.; RODRIGUES, C.; BORGES, J. D. Isotermas de sorção de metais pesados em solos do cerrado de Goiás. Revista Brasileira de Engenharia Agrícola e Ambiental, Campina Grande, v. 14, n. 7, p. 776781, 2010a.

OLIVEIRA, L. F. C.; LEMKE-DE-CASTRO, M. L.; RODRIGUES, C.; BORGES, J. D. Adsorção e deslocamento do íon cádmio em solos do cerrado. Revista Brasileira de Engenharia Agrícola e Ambiental, Campina Grande, v. 14, n. 8, p. 848-855, 2010 b.

OLIVEIRA, V. A. DE (Coord.). Manual técnico de pedologia. 2. ed. Rio de Janeiro: IBGE, 2007. 300p. (Manuais Técnicos em Geociências, 4).

PHILIPPI JÚNIOR. A.; AGUIAR, A. O. Resíduos sólidos: características e gerenciamento. In: PHILIPPI JÚNIOR. A. (Ed.). Saneamento, saúde e ambiente. São Paulo: Manole, 2005. cap. 8, p. 267- 321.

RESENDE, M.; CURI, N.; RESENDE, S. B.; CORREAA, G. F. Pedologia: base para distinção de ambientes. Viçosa: NEPUT, 1997. 367p.

RODRIGUES, C. Avaliação de dispersantes químicos e pré-tratamentos na determinação de argila de solos de mineralogia distintas. 2008. 96f. Dissertação (Mestrado em Agronomia: Solo e Água) - Escola de Agronomia e Engenharia de Alimentos, Universidade Federal de Goiás, Goiânia, 2008.

SANTOS, R. D. DOS; LEMOS, R. C. DE; SANTOS, H. G. DOS; KER, J. C.; ANJOS, L. H. C. DOS. Manual de descrição e coleta de solo no campo. 5. ed. Viçosa: SBCS/ SNLCS, 2005. $100 \mathrm{p}$.

SELBACH, P. A.; TEDESCO, M. J.; GIANELlO, C.; CAVALlET, L. E. Descarte e biodegradação de lodos de curtume no solo. Revista do Couro, Estância Velha, v. 4, p. 51-62, 1991.

SODRÉ, F. F.; LENZI, E.; COSTA, A. C. S. Utilização de modelos físico-químicos de adsorção no estudo do comportamento do cobre em solos argilosos. Química Nova, São Paulo, v. 24, n. 3, p. 324-330, 2001.

SOUZA, R. S.; CHAVES, L. H. G.; FERNANDES, J. D. Adsorção de zinco e sua relação com características de solos do Estado da Paraíba. Revista Brasileira de Ciências Agrárias, Recife, v. 1, n. 1, p. 1-6, 2006. 